\title{
Aprendizagem de línguas como sistema adaptativo complexo: análise de narrativas e proposta de intervenção
}

\author{
Catalina Henao López ${ }^{1}$ \\ Emídio Júnior Santos Bahia ${ }^{2}$ \\ Walkyria Magno e Silva ${ }^{3}$
}

Programa de Pós-Graduação em Letras, Universidade Federal do Pará, Belém, Pará, Brasil

Resumo: Recentemente tem-se afirmado o entendimento do processo de aprendizagem de línguas como um sistema adaptativo complexo (LARSEN-FREEMAN, 1997; LARSEN-FREEMAN; CAMERON, 2008; PAIVA; NASCIMENTO, 2009; MAGNO E SILVA; BORGES, 2016). Narrativas de aprendizagem têm sido usadas como importantes fontes de conhecimento sobre como isso se dá. Este artigo discute situações ocorridas em dois processos de aprendizagem que os caracterizam como esse tipo de sistema, apontando algumas intervenções que poderiam ser sido realizadas para alterar seu curso. $O$ texto começa com uma revisão teórica sobre o paradigma da complexidade e sobre o ensino-aprendizagem de línguas, seguida de uma análise de duas narrativas de aprendizagem de línguas das quais emerge uma proposta de intervenção que pode ser utilizada pelos professores (ou outros agentes) em situações análogas com o intuito de dinamizar o sistema de aprendizagem de seus estudantes.

Palavras-chave: Narrativas de aprendizagem; Sistemas adaptativos complexos; Intervenção na aprendizagem de línguas; Complexidade.

Title: Language learning as complex adaptive systems: narrative analysis and action proposals

Abstract: In the last decades, language learning processes have been understood by many authors as complex adaptive systems (LARSEN-FREEMAN, 1997; LARSEN-FREEMAN; CAMERON, 2008; PAIVA; NASCIMENTO, 2009; MAGNO E SILVA; BORGES, 2016). Language learning narratives have been used as important sources to know how these processes evolve. This paper analyses two learning processes as complex adaptive systems, highlighting interventions that could have changed their courses of action. The text begins with a brief theoretical review on the paradigm of complexity and language teaching and learning, followed by the analysis of two language learning narratives from which proposals of intervention emerge. Such proposals can be used by teachers (or other agents) in similar situations in order to stimulate the learning system of their students.

Keywords: Language learning narratives; Complex adaptative systems; Intervention in language learning; Complexity.

\footnotetext{
${ }^{1}$ Mestre em Letras (Universidade Federal do Pará). Orcid: https://orcid.org/0000-0003-1739-3587 E-mail:282cata@gmail.com

2 Especialista em "Língua portuguesa: uma abordagem textual" (Universidade Federal do Pará).

Orcid: https://orcid.org/0000-0002-5742-6948

E-mail: emidiobahia@hotmail.com

${ }^{3}$ Doutora em Ciências da Linguagem (Universidade de Toulouse le Mirail, França), Universidade Federal do Pará. Orcid: https://orcid.org/0000-0001-8572-147X

E-mail: walkyriamagno@gmail.com
} 


\section{Introdução}

Nas últimas duas décadas tem havido um movimento na direção compreender a aprendizagem de línguas como um sistema adaptativo complexo, como é possível constatar no crescente número de estudos no campo da Linguística Aplicada desde Larsen-Freeman (1997), como Larsen-Freeman e Cameron (2008), Paiva e Nascimento (2009), Magno e Silva e Borges (2016), Ortega e Zhaohong Han (2017). Esses estudos têm demonstrado que a aprendizagem envolve múltiplas variáveis que interagem entre si, tais como o contexto, os agentes, a motivação etc., e têm possibilitado a compreensão de que o sucesso na aprendizagem de línguas vai além da presença de um bom professor e de um bom método, tal como já anunciaram Prabhu (2003) e Kumaravadivelu (2006). Portanto, considera-se hoje que a aprendizagem está mais próxima da imprevisibilidade (PRABHU, 2003) típica dos sistemas complexos.

Na mesma perspectiva, essas discussões começam a representar um apoio fundamental para as práticas dos professores de línguas, uma vez que, ao compreenderem a aprendizagem como resultado de um processo complexo de interação entre diversos elementos (um sistema complexo), o papel destes passa a ser não mais o de centralizadores da atividade didática, mas o de dinamizadores de aprendizagens. Eles, então, como agentes do sistema, têm entre seus objetivos principais os de identificar as dinâmicas de aprendizagem dos alunos e os de tentar potencializa-las por meio de intervenções que correspondam às necessidades de aprendizagem que emergem nos sistemas de aprendizagem dos estudantes. São suas tarefas: compreender os alunos (suas identidades emergentes, seus estilos de aprendizagem, suas estratégias, suas motivações ...), os contextos (sala de aula, escola, casa, redes sociais...), os agentes (professores, pais, colegas, tios, vizinhos, amigos...) etc., e a partir dessa identificação e dessa compreensão intervir para dinamizar a aprendizagem dos alunos. Para melhor compreender essas dinâmicas, um dos instrumentos que podem ser utilizados pelos professores é a narrativa de aprendizagem de línguas.

Este artigo pretende demonstrar como esse tipo de narrativa, se empregada sob a perspectiva do paradigma da complexidade, pode ser um instrumento plausível (PRABHU, 1987) para professores dinamizadores de aprendizagens gerarem novas perspectivas de intervenção na sala de aula. Para demonstrar isso, analisamos duas narrativas de aprendizagem de várias línguas (tanto materna quanto estrangeiras), que foram escritas por dois professores ${ }^{4}$, identificando as características que nelas emergem, a relação delas com a abordagem da complexidade, e ainda especulando sobre alguns aspectos importantes que poderiam, a partir de ações de professores em situações similares no futuro, catalisar desdobramentos positivos nas trajetórias de aprendizagem de seus alunos.

Para isso, inicialmente tratamos da Teoria da Complexidade, mais especificamente dos Sistemas Adaptativos Complexos, e como esse conceito foi apropriado pela Linguística

\footnotetext{
${ }^{4}$ As narrativas de aprendizagem utilizadas são de autoria dos dois primeiros autores deste texto.
} 
Aplicada no âmbito do processo de aprendizagem de línguas. Em seguida, descrevemos a metodologia para a realização do estudo e, na sequência, fazemos a análise e a discussão das narrativas na perspectiva dos Sistemas Adaptativos Complexos, indicando algumas possibilidades de intervenção. Por fim, fazemos algumas considerações acerca da riqueza de possibilidades que tal enfoque pode suscitar.

\section{Sistemas adaptativos complexos e ensino/aprendizagem de línguas}

A origem do pensamento complexo, enquanto teoria baseada em uma unidade científica específica, é de difícil apontamento. Diane Larsen-Freeman, uma das precursoras na compreensão da aprendizagem de línguas enquanto sistema adaptativo complexo, já assinalou a impossibilidade de se atribuir à Teoria da Complexidade uma única fonte originária em virtude dos seus muitos antecedentes em diversos campos. Entre eles, pode-se elencar a Química (com llya Prigogine e suas pesquisas sobre os sistemas dissipativos), a Física (com Hermman Haken e seu estudo sobre Sinergética), a Biologia (com Ludwig von Bertalanffly e o seu trabalho sobre a Teoria Geral dos Sistemas), a Matemática (René Thom e a Teoria das Catástrofes)... (LARSEN-FREEMAN, 2017) os quais assentaram as bases do pensamento complexo e iluminam a nossa compreensão atual sobre o tema.

A Teoria da Complexidade abarca, conforme Larsen-Freeman e Cameron (2008), o estudo dos sistemas complexos. Por sistemas complexos entendemos os sistemas constituídos por um conjunto de elementos interdependentes que interagem entre si de modo a formar uma rede e que apresentam propriedades emergentes, comportamentos, níveis de organização que impossibilitam ao observador a previsão exata de suas ações. Essa é uma teoria sistêmica cujo objetivo é compreender fenômenos complexos do universo, que além de possuírem as propriedades comuns dos sistemas complexos (níveis de organização e propriedades emergentes que impossibilitam a previsão de suas ações) apresentam ainda a capacidade de ajustar-se às mudanças e transições que ocorrem em seus ambientes constitutivos.

Recentemente, o pensamento complexo tem obtido bastante atenção na Linguística Aplicada, principalmente após a publicação do artigo seminal de Diane Larsen-Freeman (LARSEN-FREEMAN, 1997) que relacionou complexidade e aquisição de línguas. Nesse artigo, a autora forneceu uma perspectiva teórica que permitiu descrever e explicar os fenômenos que emergem em sistemas dinâmicos, como a aprendizagem. Isso possibilitou uma explicação mais plausível para as mudanças e evoluções que acontecem no processo de aprendizagem de línguas. A ideia para esse artigo, conforme menciona a autora em uma publicação recente (LARSEN-FREEMAN, 2017), teve sua origem no momento em que ela se deparou com uma declaração no livro de James Gleick "Chaos: Making a New Science", a qual dizia: "não- 
linearidade significa que $\mathrm{o}$ ato de jogar o jogo pode acabar mudando as regras ${ }^{5 "}$. Essa declaração levou-a a pensar uma concepção diferente de língua, baseada no entendimento de língua como fenômeno complexo, embora o livro não fizesse referência direta à ideia de língua.

Essa nova compreensão ressalta que a relação entre a mudança ao longo do tempo e o processamento em tempo real é de vital importância para o estudo da aquisição de línguas ao mostrar que os padrões da língua surgem nas interações dos indivíduos que adaptam os seus recursos linguísticos ao contexto que, por sua vez, também se encontra em constante mudança. Assim, o uso significativo da língua pode alterar os recursos linguísticos do falante e estes recursos, por sua vez, se tornam elementos disponíveis para o próximo ato de fala (LARSEN-FREEMAN, 2010). Dessa forma, compreende-se que tudo o que é percebido é, na realidade, dependente das condições iniciais, ou seja, do momento em que é manifestado, pois a natureza mutável da língua faz com que as percepções se atualizem constantemente e com que as condições iniciais dessa nova situação sejam alteradas (LARSEN-FREEMAN, 2017).

Para compreendermos melhor o que são essas condições iniciais apontadas por Larsen-Freeman e os próprios sistemas complexos, enumeramos brevemente algumas de suas características. Segundo Borges e Magno e Silva (2016), os sistemas complexos têm: abertura, que é a capacidade de um sistema de se manter em constante circulação de entrada e saída de energia; dinamismo, que é a capacidade do sistema de mudar com o tempo em relação a seu estado inicial; coadaptação, que é a capacidade do sistema de aprender nas trocas de energia e na experiência com seus elementos internos e externos; sensibilidade às condições iniciais, que se refere ao fato de que às vezes influxos insignificantes em um sistema podem produzir enormes consequências; auto-organização, que é a maneira com que o sistema responde aos influxos do entorno e volta a encontrar uma estabilidade dinâmica; sensibilidade ao feedback, que indica que o sistema é suscetível às reações que provoca.

É, então, a partir da discussão lançada por Larsen-Freeman, na qual se faz referência à utilização das características dos sistemas complexos para entender o processo de aprendizagem de línguas, que a Teoria da Complexidade começa a permear o ensino de línguas, especialmente ao evidenciar que existe um número incontável de fatores (como idade, motivação, estratégias de aprendizagem, estilos cognitivos, contextos em que a língua é aprendida, tipos de interação com a língua, entre outros) que interagem e determinam a trajetória que está sendo desenvolvida (LARSEN-FREEMAN, 1997), influenciando tanto positiva quanto negativamente o processo aprendizagem.

O crescente interesse nesta teoria para explicar os processos não-lineares envolvidos na aprendizagem de línguas deve-se talvez ao seu poder em explicar porque os mesmos indivíduos desenvolvem trajetórias tão díspares em situações multilíngues. Opitz (2017) relata o caso de quatro adultos aprendendo línguas diferentes abrangendo diversas escalas de

\footnotetext{
${ }^{5}$ Conforme a citação no original: "'nonlinearity means the act of playing the game has a way of changing the rules" (LARSEN-FREEMAN, 2017, p. 17).
} 
tempo. O estudo conclui que tanto a estabilidade dinâmica quanto saltos qualitativos são possíveis para um mesmo indivíduo, dadas as diferenças de fatores contextuais e pessoais.

Para finalizar esta seção, é necessário esclarecer que a teoria da complexidade não pretende ser impositiva ou se constituir em um método para orientar o ensino de línguas estrangeiras (LARSEN-FREEMAN; CAMERON, 2008; PAIVA; NASCIMENTO, 2009). O objetivo é oferecer uma mudança de perspectiva sobre a forma como os processos sistêmicos mentais e sociais de aprendizagem ocorrem. Isso, a fim de gerar uma transformação, por um lado, na maneira como os professores percebem o processo de seus alunos e mesmo seu próprio trabalho docente, e, por outro, na forma como os alunos se veem a si mesmos no processo de aprender uma língua.

Passemos então à descrição da metodologia empregada neste estudo, fazendo relação dessa com alguns pressupostos importantes da pesquisa em complexidade.

\section{Metodologia e paradigma da complexidade}

Conforme mencionado anteriormente, o paradigma da complexidade abarco o estudo de sistemas adaptativos complexos, elencando os tipos de elementos que os compõem e que interferem em seu desenvolvimento. Segundo mencionam os estudiosos que abraçam este paradigma, a pesquisa conduzida sob essa lente deve partir do princípio de que existem sistemas que estão interligados, que se auto-organizam e que podem apresentar comportamentos emergentes a partir das diferentes interações entre os elementos que os compõem. Logo, o pesquisador trabalhando nessa perspectiva tem como tarefa fundamental descrever as relações existentes no sistema, tornando explícitas as suas dinâmicas, tal como recomendam Larsen-Freeman e Cameron (2008).

Para conduzir um processo de investigação nesse prisma é preciso usar ferramentas que possibilitem descrever a trajetória de um sistema. Na Linguística Aplicada, a narrativa de aprendizagem tem sido um instrumento bastante utilizado nas investigações desse tipo, o que a habilita como um objeto de estudo da complexidade, como bem ilustrado por Paiva (2005). Essa mesma autora editou um número especial da Revista Brasileira de Linguística Aplicada com trabalhos que lançam mão de narrativas de aprendizagem (PAIVA, 2008). Uma das características fundamentais da pesquisa em complexidade é a observação longitudinal e a narrativa possibilita essa verificação, pois abarca as experiências do passado, presente e futuro. Cruz (2015), ao tratar do princípio da continuidade, ressalta a conexão entre as experiências desses três tempos numa mesma narrativa de aprendizagem.

As duas narrativas de aprendizagem de línguas que utilizamos neste estudo se constituem ao mesmo tempo como instrumento de construção de dados, corpus e objeto de estudo. É por meio delas que realizamos a análise das interações dos elementos do processo e extraímos as informações relevantes para as intervenções didáticas que, segundo 
acreditamos, podem auxiliar positivamente na aprendizagem de línguas.

Por "narrativa de aprendizagem de línguas", corroboramos com o conceito de Cruz (2015) que afirma ser ela um instrumento por meio do qual o sujeito atribui sentido às suas experiências que ocorrem dentro e fora da sala de aula de línguas e as reconstrói por meio da escrita. Essas experiências plasmadas nas narrativas que constituem nosso corpus e que representam as trajetórias de aprendizagem de línguas de dois dos autores são o ponto de partida para a identificação dos elementos que estão agindo e interagindo no sistema. Logo, analisar essas narrativas nos permite visualizar mais claramente o funcionamento desse sistema, quais os seus affordances ${ }^{6}$, os seus fluxos de energia que representam os aspectos de motivação e desmotivação, em quais contextos esses affordandes emergem, que agentes estão envolvidos nesse processo e quais as ações que mobilizam esses comportamentos. Tudo isso nos motivou para que utilizássemos essas narrativas em nossa análise, uma vez que elas constituem "fonte única de informações sobre as motivações, experiências, lutas, perdas e ganhos" conforme nos aponta Pavlenko (apud SANTOS; MAGNO E SILVA, 2016, p. 146). Assim, uma análise de narrativas de aprendizagem de línguas pode ser extremamente útil para identificação dos estados dos processos de aprendizagem, fornecendo pistas ao professor para intervenções didáticas visando potencializar as aprendizagens dos alunos.

No que concerne à análise, esta foi realizada com base no que estabelecem Lieblich, Tuval-Mashiach e Zilber (1998) para a leitura, análise e interpretação na pesquisa com narrativas. Para as autoras, a análise e interpretação de narrativas é realizável por meio de dois pares de dimensões: holística versus categorial e conteúdo versus forma. Essas dimensões se combinam e formam quatro matrizes que se constituem no cruzamento dessas abordagens, a saber: holística-conteúdo, holística-forma, categorial-conteúdo e categorialforma. O modelo escolhido para esta análise foi o categorial-conteúdo, cujas categorias foram identificadas a partir de sucessivas leituras das duas narrativas do corpus.

Das categorias recorrentes, identificadas nas narrativas, escolhemos três que, para nós, representam possíveis chaves dinamizadoras das aprendizagens dos alunos e que podem ser um dos alvos do processo de intervenção dos professores: affordances, aspecto motivacional e sensibilidade ao feedback; as quais serão focalizadas em nossa análise.

Além disso, uma informação relevante com relação às narrativas de aprendizagem que constituem instrumento de construção de dados, corpus e objeto é que elas não foram feitas especialmente para este artigo. Foram escritas no início de uma disciplina do curso de mestrado intitulada "Aprendizagem de Línguas sob o Paradigma da Complexidade", ministrada pela terceira autora deste texto no Programa de Pós-Graduação em Letras da Universidade Federal do Pará. A intenção da professora ao solicitar a tarefa era possibilitar aos discentes uma reflexão mais aprofundada para compreender a complexidade, a fim de que, ao final desse curso, eles pudessem analisar suas próprias trajetórias de aprendizagem à

\footnotetext{
${ }^{6}$ Definido por van Lier (2000, p. 257) como "a relação entre as propriedades do ambiente e o aprendiz ativo".
} 
luz da complexidade, compreendendo a emergência dos componentes dos sistemas adaptativos complexos. Dessa reflexão, evidenciou-se a necessidade de reportar os aspectos que mencionaremos a seguir.

\section{Análise de narrativas e possibilidades de intervenção na aprendizagem de línguas}

As características dos sistemas complexos que emergiram na leitura das narrativas foram: sistema aberto, não-linear, dinâmico, sensível às condições iniciais, (co)adaptativo, auto-organizado, com affordances, imprevisível e sensível ao feedback. Como afirmamos em nossa metodologia, dessas escolhemos três categorias: affordances, motivação e sensibilidade ao feedback. Passemos então à análise das narrativas e à discussão dessas três categorias.

\section{Affordances}

A primeira categoria, affordances, foi identificada como importante em ambas as narrativas analisadas. Inicialmente, conceituamos o que vem a ser affordance e em seguida fazemos a discussão relacionando excertos das narrativas com a categoria em questão. Por fim, especulamos como essa categoria pode ser alvo de ação/intervenção do professor em situações que sigam padrões similares aos desvelados nas narrativas ora em foco.

Em acordo com van Lier (2000, p. 252), entendemos affordance como uma "propriedade particular do ambiente que é relevante, para o bem ou para o mal, do ponto de vista de um organismo ativo e perceptivo naquele ambiente". Essa propriedade influencia na agência ${ }^{7}$ de um sistema complexo. Dessa forma, affordance faz referência direta ao contexto em que o sujeito está inserido e pode ser negativo ou positivo para o processo de aprendizagem por condicionar a agência do sujeito, embora não de forma decisiva. Isso quer dizer, por exemplo, que restrições contextuais podem influenciar a agência do indivíduo com implicações desfavoráveis à aprendizagem, como também pode acontecer que essas mesmas restrições, em outro indivíduo ou para o mesmo indivíduo em um contexto diferente, resultem em criatividade ao catalisar meios para aprender (VIANINI, 2016). Logo, affordance diz respeito ao processo relacional entre contexto e sujeito, aliado às condições disponíveis no ambiente para a agência do indivíduo.

Vejamos abaixo o Quadro 1 que traz dois excertos importantes para identificar essa categoria no sistema:

\footnotetext{
${ }^{7}$ Segundo van Lier (2008) agência refere-se ao que os aprendentes fazem, ao comportamento deles regulado pelo contexto sociocultural.
} 
Quadro 1 - Affordances identificadas nas narrativas

\begin{tabular}{|c|c|c|}
\hline \multirow{2}{*}{ CATEGORIA } & \multicolumn{2}{|c|}{ EXCERTOS DAS NARRATIVAS } \\
\hline & CATALINA & EMÍDIO \\
\hline Affordance & $\begin{array}{l}\text { a. Com o tempo, os semestres } \\
\text { transcorreram e a complexidade cada vez } \\
\text { foi maior; até que chegamos ao quarto } \\
\text { semestre e o professor do último nível de } \\
\text { inglês nos exigiu só falar em inglês durante } \\
\text { as aulas -ninguém tinha feito isso antes por } \\
\text { essa história de que os tradutores não } \\
\text { temos por que aprender a falar se nosso } \\
\text { trabalho só abrange os textos.[...] Só nesse } \\
\text { momento descobri que tinha muita } \\
\text { dificuldade para falar. Eu achava que sabia } \\
\text { muitas coisas, mas no momento de falar } \\
\text { não saiam de minha boca. } \\
\text { b. [...] Quando foi o momento da minha } \\
\text { (formatura), e eu não podia continuar como } \\
\text { monitora porque não seria mais estudante, } \\
\text { meu chefe me pediu ficar lá como } \\
\text { professora. Eu estava muito assustada mas } \\
\text { aceitei e tive que continuar com o processo } \\
\text { de estudar para que fosse tão claro para } \\
\text { mim que minhas explicações pudessem } \\
\text { refletir essa claridade. Hoje, acho que ter } \\
\text { sido professora de inglês me levou a ter um } \\
\text { bom nível mas sinto que há muito tempo } \\
\text { que tenho o mesmo conhecimento e não } \\
\text { tenho encontrado a maneira de sair dessa } \\
\text { zona de estagnação. }\end{array}$ & 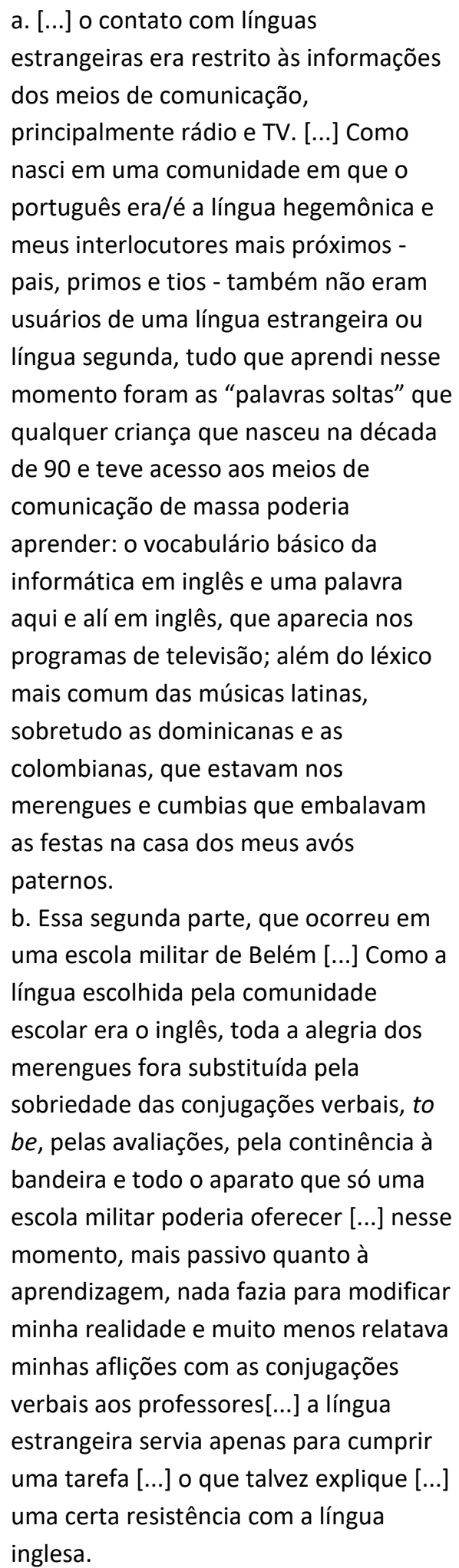 \\
\hline
\end{tabular}


No Quadro 1 trazemos excertos das duas narrativas que mostram a presença de affordances nos processos de aprendizagem. Observando as particularidades de cada uma, no trecho a de Catalina observa-se que devido a um affordance negativo que não propiciava o desenvolvimento da fluência oral, ela nunca se deparou com a necessidade de falar a língua alvo. Isso só aconteceu quando houve uma mudança no contexto, quase no fim da sua graduação, tornando evidente o dinamismo do sistema. Por outro lado, no exemplo b de Catalina observamos que ela menciona ter atingido um nível significativo em inglês, e que após atingir esse patamar teve a sensação de estar há um longo tempo sem alterar aquele estado do conhecimento e que não encontrava o caminho para sair desse espaço de "estagnação". Essa descrição refere-se a um padrão de comportamento ou à continuidade de um estado, segundo é possível verificar na narrativa, do affordance disponível para a agência de Catalina, o qual não propiciava a energia suficiente para mover o sistema até um estado favorável à emergência de novos conhecimentos.

No caso de Emídio, no trecho a observa-se affordances favoráveis à aprendizagem de línguas, inglês e espanhol, que mobilizavam a agência do seu sistema. Os meios de comunicação, programas de televisão e o acesso à informática propiciavam o contato com o léxico da língua inglesa que o contexto sociocultural e imediato não propiciava. Este favorecia a agência para a aprendizagem da língua espanhola, com o contato com as músicas latinas na casa de seus avós, constituindo affordance positivo à aprendizagem. Já no trecho b, o contexto "escola militar" disponibilizava affordances que não mobilizavam a agência do sistema de aprendizagem de Emídio para o inglês; "conjugações verbais", "avaliações", "continência à bandeira" representam affordances negativos para a agência de Emídio que "nada fazia para modificar" a sua realidade e as suas "aflições" acerca da aprendizagem da língua inglesa.

Para entendermos melhor as agências dos sujeitos nesses affordances é importante destacar os contextos de emergência dessas agências, uma vez que eles (os contextos) são, dentro da complexidade, elementos ativos do sistema e não simplesmente cenários para os acontecimentos.

No caso de Catalina, em primeiro lugar, consegue-se perceber o papel do contexto para o não desenvolvimento da competência oral e, também a transformação positiva na sua agência quando esse contexto muda. Ao se deparar com um professor que lhe exigia falar, ela nota o quanto havia desatendido a oralidade na língua estrangeira por conta, em grande parte, da falta de espaços para se comunicar. Em segundo lugar, ela menciona que houve um salto qualitativo em seu nível de inglês causado pelo fato de ter sido nomeada professora, quando se percebe um affordance que estimulou sua agência positivamente em prol da aprendizagem. Logo depois, identifica-se mais uma vez um affordance negativo, quando o nível se manteve inalterado, em grande parte, por conta do contexto que não a provocava para aprofundar seus conhecimentos. Ao ser convocada para trabalhar em uma instituição universitária, Catalina viu-se na necessidade de se coadaptar ao contexto que exigia um conhecimento considerado elevado da língua inglesa e logo após esse estado coadaptativo o 
sistema de aprendizagem de inglês estabilizou-se, entrando em um estado de equilíbrio dinâmico.

No caso de Emídio, o contexto sociocultural e imediato, as festas na casa dos avós, com músicas latinas, têm significativa influência na aprendizagem de espanhol uma vez que é em virtude desse contexto que as oportunidades de aprender acontecem. Os ritmos das músicas, a alegria dos participantes, dentre outros múltiplos fatores que emergem nesse contexto de festa traziam a Emídio as oportunidades, as motivações, os affordances que mobilizavam a sua agência para a aprendizagem. Assim também se deu com o acesso aos meios de comunicação de massa nos anos 90 e à internet que propiciava a aprendizagem do léxico em inglês que o contexto familiar não disponibilizava. Já a "escola militar" representava um contexto desfavorável à aprendizagem, como vimos. As atividades didáticas de conjugação verbal, somadas às avaliações (que tinham uma finalidade menos formativa), agregadas à rigidez militar representavam affordances desfavoráveis que influenciavam na agência de Emídio, fazendo com que este nada fizesse para sair do estado de resistência à aprendizagem de língua inglesa. Alinhado a isso, havia ainda o fato de outros affordances ligados à aprendizagem da língua espanhola emergiram em contextos favoráveis, o que possivelmente direcionou a energia do sistema para essa língua, contrastando com as condições de aprendizagem do inglês.

É importante notar que a identificação do quadro acima com affordances e contextos de emergência é extremamente relevante uma vez que a focalização nos affordances e nos estados de aprendizagem deles resultantes mostraram, de certa forma, os estados em que o sistema se encontrava - quais elementos, em interação, estão gerando determinados estados favoráveis ou desfavoráveis, a que pontos do sistema a energia está direcionada e se há affordances e contextos desfavoráveis à aprendizagem. Essas situações revelam possíveis focos para a intervenção por parte do professor ou até de outros agentes como o próprio aluno ou um conselheiro linguageiro ${ }^{8}$ e constitui a primeira parte de nossa proposta de intervenção nos processos de aprendizagem. No caso de Catalina, notamos que os affordances relativos à estagnação na aprendizagem da língua inglesa permaneceram em vigor. No caso de Emídio, affordances ligados à memória da infância parecem inserir mais energia e dinamicidade no sistema de aprendizagem de espanhol do que no de inglês. Uma entrada de energia no sistema de Emídio que modificasse o estado anteriormente apresentado, assim como no de Catalina, poderiam ter gerado uma agência favorável à aprendizagem.

Desse modo, corroborando o que dizem Borges e Magno e Silva (2016), como os sistemas complexos são sensíveis às perturbações, sejam grandes ou pequenas, externas ou internas, eles são, portanto, sensíveis às variações de energia, o que nos indicaria uma possível segunda parte de proposta de ação/intervenção: a entrada de energia no sistema, que para nós pode ser representada pelos aspectos motivacionais que poderiam injetar, segundo

\footnotetext{
${ }^{8}$ Considera-se o conselheiro linguageiro mais um agente do sistema de aprendizagem de línguas. Para mais detalhes ver Magno e Silva (2016).
} 
acreditamos, energia suficiente no sistema para modificar esses estados desfavoráveis apresentados nas narrativas para um estado mais favorável à aprendizagem. É certo que este é um condicional impossível para estas trajetórias que já foram traçadas, mas, como padrões de comportamento tendem a surgir nos sistemas de aprendizagem, agentes do sistema, cientes dessas possibilidades, poderiam manter sua atenção na identificação de estados com menos dinamismo e facilitar a identificação de affordances mais favoráveis.

\section{Motivação}

Aprofundando a questão da energia insuflada no sistema pelos aspectos que motivam os aprendentes, passamos à segunda categoria abordada neste estudo. Antes de iniciarmos a leitura do Quadro 2 é importante estabelecer que nos alinhamos ao posicionamento de Dörnyei para quem a motivação é um "estado de alerta cumulativo, dinamicamente mutante em um indivíduo, que começa, direciona, coordena, amplifica, termina e avalia os processos cognitivos e motores por meio dos quais vontades e desejos iniciais são selecionados, priorizados, operacionalizados e desempenhados (com ou sem sucesso)" (DÖRNYEI, 20002011, p. 209). Desse posicionamento, compreendemos a motivação como um elemento do sistema que catalisa um fluxo de energia diretamente ligado a comportamentos que influenciam o processo de aprendizagem. Destacamos os excertos das narrativas de aprendizagem que poderiam exemplificar esse processo no quadro abaixo.

Quadro 2 - Motivação para aprendizagem de línguas

\begin{tabular}{|c|c|c|}
\hline \multirow{2}{*}{ CATEGORIA } & \multicolumn{2}{|c|}{ EXCERTOS DAS NARRATIVAS } \\
\hline & CATALINA & EMIDIO \\
\hline Motivação & $\begin{array}{l}\text { a. Comecei a descobrir o mundo da } \\
\text { gramática espanhola, e adorei. } \\
\text { b. Desde pequena desenvolvi um } \\
\text { certo interesse pelas línguas. } \\
\text { c. Comecei a ir para as aulas e } \\
\text { gostei muito, tanto da língua } \\
\text { quanto dos professores e os } \\
\text { companheiros. } \\
\text { d. Acho que esse amor e interesse } \\
\text { que eu tinha por ir nas aulas ajudou } \\
\text { muito para que eu conseguisse } \\
\text { aprender a língua. } \\
\text { e. Todo esse tempo (dois anos) } \\
\text { passei sem ter quase nenhum } \\
\text { contato com a língua. }\end{array}$ & $\begin{array}{l}\text { a. Foi nesse primeiro momento, sem dúvida, que } \\
\text { a minha afeição pelas línguas românicas } \\
\text { começou a florescer, pois os entoares melódicos } \\
\text { das flores do Lácio estão impregnados de uma } \\
\text { memória afetiva da infância [...] o que talvez } \\
\text { explique a minha afinidade com as línguas } \\
\text { românicas - e a escolha de aprender francês e } \\
\text { fazer uma graduação nessa área [...] } \\
\text { b. Como a língua escolhida pela comunidade } \\
\text { escolar era o inglês, toda a alegria dos } \\
\text { merengues fora substituída pela sobriedade das } \\
\text { conjugações verbais, to be, pelas avaliações, pela } \\
\text { continência à bandeira e todo aparato que só } \\
\text { uma escola militar poderia oferecer }\end{array}$ \\
\hline
\end{tabular}


Vemos no quadro os estados de motivação que foram destacados nas narrativas. Houve uma presença significativa de elementos motivacionais nos sistemas de aprendizagem, com perdas e ganhos de energia; o que nos leva a crer que, em geral, há uma tendência emergente desse elemento que é resultado, segundo observamos, da interação com agentes que influenciam o sistema de aprendizagem de línguas. Silva (2008) menciona a importância do trabalho colaborativo direcionado para manter a motivação em grupos de aprendizagem, no seu caso em comunidades virtuais.

Nos excertos da narrativa de Catalina, há quatro exemplos de processos de motivação, de ganho de energia, e um de perda de energia, de entropia. Nos primeiros dois itens, a e b, Catalina menciona que o processo motivacional surge do próprio interesse e gosto pelas línguas, e que, de acordo com a narrativa, posteriormente, resulta em ações de aprendizagem autônoma. No item c, a autora destaca professores e colegas como agentes que interagem com o sistema para gerar uma resposta positiva no aumento da energia, corroborando Silva (2008). Este autor ressalta o papel dos agentes dinamizadores do sistema, cuja ação ou, em alguns casos, provocação, pode tirar o sistema de uma aparente estabilidade. Caso nada ocorra para alterar essa trajetória, o sistema pode estagnar e, em alguns casos, se extinguir. Já no item d, mostra uma relação entre o fato de desfrutar de aulas e da aprendizagem da língua, de tal modo que acredita que isso teve um impacto sobre seu processo de aprendizagem. Já no item e, expõe o processo desmotivacional como entrópico, o que pode fazer com que o sistema entre num estado desfavorável à aprendizagem.

Já nos excertos da narrativa de Emídio, vemos no item a que as memórias da infância formam um estado motivacional de ganho de energia, que sustenta uma maior afinidade pelas línguas românicas, levando-o a ter facilidade de aprendizagem destas e ainda o levam a aprender francês e cursar uma graduação nessa língua. Já no item b, o agente "comunidade escolar", o contexto da escola militar e as atividades didáticas nele empreendidas formaram um conjunto de elementos entrópicos que resultaram na desmotivação para a aprendizagem de inglês.

Ao olhar para os contextos de emergência da categoria motivação, vemos, no caso da narrativa da Catalina, que os itens a e $\mathbf{b}$ aconteceram imprevisivelmente na vida da autora, um comportamento emergente do próprio sistema que aparentemente parece não estar ligado a processos de educação formal. Portanto, eles representam nesse quadro contextual um interesse pessoal pela aprendizagem ou desenvolvimento de línguas (no caso espanhol). No trecho c, se observa que a educação formal gera motivação pois está apoiada pelo fato de que os agentes nela envolvidos (companheiros e professores) produzem nela uma vontade de estar imersa nesse contexto. Esse exemplo mostra como as interações entre os elementos do sistema, envolvendo principalmente elementos geradores de energia motivacional, podem influenciar na sua trajetória, corroborando os achados de Silva (2008). No extrato d, a autora revela que é consciente de que o contexto "sala de aula" (incluindo aí seus agentes) influenciou sua motivação, o que de certo modo auxiliou positivamente a sua aprendizagem. 
O último item menciona um processo entrópico do sistema; a autora termina a educação formal em língua portuguesa achando que tem um bom nível, mas esse acontecimento é seguido por dois anos nos quais ela não tem nenhum contato com a língua e que a levaram a "esquecer" boa parte dos conhecimentos que tinha, o que demonstra que o sistema entrou em um processo de perda de energia que foi interrompida pela viagem da autora a um país luso-falante.

Vemos nos exemplos apresentados nas narrativas de Catalina e Emídio que os contextos e os agentes foram importantes mobilizadores de energia nos sistemas, de tal modo que modificaram relevantemente o fluxo motivacional e, provavelmente, segundo é possível concluir dos excertos, influenciaram no processo de aprendizagem dos autores. Partindo desse entendimento da possibilidade de influência do fluxo motivacional para a modificação de estados desfavoráveis à aprendizagem, é possível visualizar uma terceira parte de nossa proposta de ação/intervenção: os feedbacks mobilizados pelos agentes do sistema. Esta confirma o que diz Larsen-Freeman (1997) ao afirmar que os sistemas adaptativos complexos, como as trajetórias de aprendizagem de línguas representadas neste texto pelas narrativas de aprendizagem, são altamente sensíveis aos feedbacks.

Sensibilidade ao feedback

Passemos então à terceira categoria que emergiu de nossas narrativas, que corresponde à sensibilidade dos sistemas ao feedback, com a observação do Quadro 3, o qual traz alguns excertos representativos desse processo.

Quadro 3 - Importância do feedback para a aprendizagem

\begin{tabular}{|c|c|c|}
\hline \multirow{2}{*}{ CATEGORIA } & \multicolumn{2}{|c|}{ EXCERTOS DAS NARRATIVAS } \\
\hline & CATALINA & EMIDIO \\
\hline $\begin{array}{c}\text { Sensibilidade ao } \\
\text { feedback }\end{array}$ & $\begin{array}{l}\text { a. O professor do último nível de inglês nos } \\
\text { exigiu só falar em inglês durante as aulas. [...] } \\
\text { Ele tinha um ouvido impressionante então } \\
\text { ninguém estava a salvo da reprimenda } \\
\text { quando ele escutava uma palavra em } \\
\text { espanhol. Só nesse momento descobri que } \\
\text { tinha muita dificuldade para falar. [...] daí em } \\
\text { diante, comecei a melhorar muito minha } \\
\text { habilidade comunicativa em inglês. }\end{array}$ & $\begin{array}{l}\text { a. [...] e apresentava bastante } \\
\text { dificuldade na aprendizagem de uma } \\
\text { língua não pertencente ao grupo } \\
\text { românico [...] o que provavelmente } \\
\text { deve ter influenciado na minha } \\
\text { desistência do curso, além do fato de } \\
\text { eu não realizar boa parte da tarefa a } \\
\text { mim designada pelos professores, o } \\
\text { que também foi um fator agravante. }\end{array}$ \\
\hline
\end{tabular}


Nesse último quadro de nossa análise observamos que as narrativas apresentam cada uma um caso de sensibilidade ao feedback. Na narrativa de Catalina tal feedback teve repercussões positivas, uma vez que possibilitou a emergência da auto-organização do sistema. Já em Emídio o efeito foi diferente; a ausência de feedback decorrente da não realização da atividade pode ter sido um fator agravante, que pode ter resultado numa queda de energia e na desistência do curso de alemão. No fragmento de Catalina, vemos uma experiência relacionada com sua proficiência na modalidade oral da língua inglesa. No último ano do curso de graduação, o professor exigiu que todos os aprendentes falassem unicamente em inglês durante as aulas, o que demonstra uma modificação das condições de funcionamento do processo de aprendizagem pela ação de um agente. Isso gerou um autofeedback negativo, uma vez que a aluna se deparou com o fato de que não sabia se comunicar oralmente em inglês, o que resultou em grande perturbação no sistema e a conduziu primeiramente a uma coadaptação às condições exigidas pelo contexto e, em seguida, a uma auto-organização de seu sistema para atingir os objetivos esperados.

O contexto de emergência dessa categoria nas trajetórias de aprendizagem de línguas (e nas narrativas) são os seguintes: observando o caso de Catalina, o fato de fazer uma graduação em Tradução: Inglês, Francês, Espanhol na Universidade de Antioquia, Colômbia, o foco do curso era a aprendizagem de línguas para o propósito de traduzir textos, o que implicou que os professores não enfatizassem a oralidade em suas atividades didáticas. Isso resultou no fato de os alunos não desenvolverem as habilidades necessárias nessa modalidade. Depois da imposição das novas condições de funcionamento por um novo agente (professor) que exigiu que todos "falassem em inglês", seu sistema reagiu ao feedback, fazendo emergir novos comportamentos. Já no caso de Emídio, o curso de língua alemã era de três horas semanais, cada turma tinha pelo menos 20 alunos e a atividade didática do professor se restringia à exposição dos conteúdos. A única possibilidade de se obter um feedback sobre a aprendizagem dava-se nas duas avaliações que ocorriam no semestre, momentos que serviriam sobretudo para a constatação de um problema do que para a modificação da trajetória de aprendizagem. Logo, a ausência de agentes que mobilizassem feedbacks positivos durante o transcurso das atividades ou que modificassem as condições de funcionamento do sistema a ponto de possibilitar um auto-feedback em Emídio resultou numa perda de energia e consequente desistência do curso de alemão, segundo a narrativa. A aprendizagem de múltiplas línguas por um mesmo indivíduo segue trajetórias diferentes, dependendo da interação entre os elementos que compõem o sistema de cada processo, como demonstrado em Opitz (2017).

A ideia de sensibilidade dos sistemas ao feedback que expusemos acima com os casos de Catalina e Emídio ilumina nossa última proposta de intervenção que tenta mostrar que agentes como o professor, conselheiros linguageiros entre outros, podem atuar como dinamizadores do processo de aprendizagem dos alunos a partir de um feedback positivo ou do fomento de condições favoráveis a um auto-feedback que podem resultar em outros estados de comportamento da aprendizagem, como a auto-organização, o aumento da 
energia interna do sistema resultado de um fluxo motivacional positivo. Outra questão importante que merece ser destacada é o fato de que a "perturbação" positiva no processo de aprendizagem dos estudantes não acontece somente com a intenção de ação do professor em dinamizá-lo, pois é preciso antes, como evidenciamos anteriormente, que o professor (ou outro agente) conheça quais são as dinâmicas de funcionamento do processo, quais as seus affordances, quais elementos estão em interação e em quais contextos, para poder propor intervenções que consigam propiciar uma eventual dinâmica positiva à aprendizagem de maneira geral, e à aprendizagem de língua, nosso foco de discussão ao longo deste artigo.

Nesse sentido, a compreensão do paradigma da complexidade e suas características nos faz chegar à conclusão de que cada indivíduo percorre uma trajetória de aprendizagem de língua que pode ser representada por uma narrativa que está marcada por vários elementos constituintes, que interagem e reagem a influxos (a feedback, a agentes, ao contexto...). Logo, a aprendizagem de uma língua deve ser compreendida como um processo dinâmico, que tem avanços e retrocessos, que é caótico, que se auto-organiza e se movimenta, que alcança estados críticos e sofre mudanças imprevisíveis (DE BOT, 2008) e que pode, ao receber feedback de seus agentes, resultar num progresso de aprendizagem de fato, como nos lembra Larsen-Freeman (1997).

\section{Considerações finais}

No presente estudo foi realizada a análise de duas narrativas de aprendizagem de línguas, e como vimos, nelas emergiram diversos elementos típicos de um sistema adaptativo complexo, o que nos permitiu elucidar fatores relevantes na trajetória dos autores e descrever algumas implicações práticas a fim de demonstrar como essas narrativas, se observadas à luz do paradigma da complexidade, podem ser úteis para um professor dinamizador de aprendizagens, trazendo-lhe novas perspectivas de intervenção na sala de aula.

Essas implicações práticas, representadas pela proposta de intervenção, exposta ao longo da análise, poderiam ser realizadas por professores nos processos de aprendizagem de seus alunos. Para tal é necessário, como fizemos, uma observação inicial do funcionamento do sistema para, a partir da identificação das relações existentes entre os seus elementos, agir sobre processos de aprendizagem. Em nosso estudo, depois de visualizar o funcionamento do sistema, focalizamos na relação/interação entre as categorias emergentes que achamos mais relevantes para essa possível intervenção, as quais foram: affordances, motivação e feedback. Esta aproximação nos permitiu aprofundar a discussão em cada categoria e demonstrar como a interação do professor com o sistema do aprendente pode desatar alguns nós, visando auxiliar na modificação de estados não favoráveis à aprendizagem, dinamizando a energia do fluxo motivacional do estudante por meio de feedback ou das modificações das condições do processo, o que no caso dos processos narrados resultou em auto-organização e motivação.

Neste estudo, a narrativa de aprendizagem se mostrou um instrumento relevante para 
a análise da trajetória dos indivíduos, e principalmente, como uma chave para revelar maneiras possíveis de intervir no processo de aprendizagem de línguas dos sujeitos.

Em estudos futuros, pretendemos ampliar o escopo de estudo com foco em outros elementos que emergem de narrativas e analisar como a relação desses pode mostrar outras possíveis propostas de intervenção para a aprendizagem de línguas. Igualmente, para que façamos isso, é preciso tomar como exemplo não apenas as trajetórias dos sujeitos aqui observados, mas coletar um maior número de narrativas de outros sujeitos para compor um panorama mais rico dos fenômenos presentes na aprendizagem de línguas.

Finalmente, consideramos que embora o conhecimento desse instrumento e da teoria da complexidade no ensino-aprendizagem de línguas não sejam ainda de domínio extensivo na Linguística Aplicada, o crescente número de pesquisas pode fundamentar a utilização das narrativas como ferramentas em prol do ensino e da aprendizagem.

\section{Referências}

BORGES, Elaine Ferreira do Vale; MAGNO E SILVA, Walkyria. Introdução. Entrelaçamento de temas na compreensão de sistemas caóticos. In: MAGNO E SILVA, Walkyria; BORGES, Elaine (Orgs.) Complexidade em ambientes de ensino e de aprendizagem de línguas adicionais. Curitiba: CRV, 2016. p. 19-23.

CRUZ, Giêdra Ferreira. Narrativas de aprendizagem como recurso didático: (re)conhecendo alunos com suas histórias de vida. Revista de Letras, v. 7, n. 2, p. 287-302, 2015.

DE BOT, Kees. Introduction: second language development as a dynamic process. The Modern Language Journal, v. 92, n. 2, p. 166-178, 2008. https://doi.org/10.1111/j.1540$\underline{4781.2008 .00712 . x}$

DÖRNYEI, Zóltan. Motivação em Ação: Buscando uma conceituação processual da motivação em alunos. In: BARCELOS, Ana Maria Ferreira. (Org.) Linguística Aplicada: Reflexões sobre ensino e aprendizagem de língua materna e língua estrangeira. Campinas: Pontes, 2000-2011. P. 199-236.

KUMARAVADIVELU, Balasubramanian. Understanding Language Teaching: from method to Postmethod. Mahwah, New Jersey: Lawrence Erlbaum, 2006.

LARSEN-FREEMAN, Diane. Chaos / complexity science and second language acquisition. Applied Linguistics, v. 18, n. 2, p. 142-152, 1997. https://doi.org/10.1093/applin/18.2.141

LARSEN-FREEMAN, Diane. Having and doing: Learning from a complexity theory perspective. In: SEEDHOUSE, Paul; WALSH, Steve; JENKS, Chris (Eds.). Conceptualising learning in applied linguistics. Houndmills: Palgrave Macmillan. p. 52-68, 2010.

https://doi.org/10.1057/9780230289772 4

LARSEN-FREEMAN, Diane. Complexity Theory: The lessons continue. In: ORTEGA, Lourdes; HAN, ZhaoHong. Eds. Complexity Theory and Language Development. In celebration of Diane Larsen-Freeman. Amsterdam: John Benjamins, 2017. p. 11-50.

https://doi.org/10.1075/Illt.48.02lar 
LARSEN-FREEMAN, Diane; CAMERON, Lyn. Research methodology on language development from a complex systems perspective. The Modern Language Journal, v. 92, n. 2, p. 200-213, 2008. https://doi.org/10.1111/i.1540-4781.2008.00714.x

LIEBLICH, Amia; TUVAL-MASHIACH, Rivka; ZILBER, Tamar. Narrative research: reading, analysis and interpretation. Nova Deli: Sage, 1998. https://doi.org/10.4135/9781412985253

MAGNO E SILVA, Walkyria. Conselheiros linguageiros como potenciais perturbadores de suas próprias trajetórias no sistema de aprendizagem. In: MAGNO E SILVA, Walkyria; BORGES, Elaine Ferreira do Vale. (Orgs.). Complexidade em ambientes de ensino e de aprendizagem de línguas adicionais. Curitiba: CRV, 2016. p. 199-220.

https://doi.org/10.24824/978854441014.1

OPITZ, Conny. Language destabilization and (re-)learning from a Complexity Theory perspective. Timescales and patterns across four studies. In: ORTEGA, Lourdes; HAN, ZhaoHong (Eds.). Complexity Theory and Language Development. In celebration of Diane Larsen-Freeman. Amsterdam: John Benjamins, 2017. p. 163-189. https://doi.org/10.1075/Illt.48.09opi

ORTEGA, Lourdes; HAN, ZhaoHong (Eds.) Complexity Theory and Language Development. In celebration of Diane Larsen-Freeman. Amsterdam: John Benjamins, 2017. https://doi.org/10.1075/IIIt.48

PAIVA, Vera Lucia Menezes de Oliveira e. Revista Brasileira de Linguística Aplicada, v. 8, n. 2. Belo Horizonte, 2008. https://doi.org/10.1590/S1984-63982008000200004

PAIVA, Vera Lucia Menezes de Oliveira e. Modelo fractal de aquisição de línguas. In: BRUNO, Fátima Cabral (Org.) Reflexão e prática em ensino/aprendizagem de língua estrangeira. São Paulo: Editora Clara Luz, 2005. p. 23-36.

PAIVA, Vera Lúcia; NASCIMENTO, Milton. (Orgs.) Sistemas adaptativos complexos: lingua(gem) e aprendizagem. Belo Horizonte: Faculdade de Letras/FAPEMIG, 2009.

PRABHU, Nagore S. Second language pedagogy. Oxford: Oxford University Press, 1987.

PRABHU, Nagore S. Ensinar é, no máximo, esperar que o melhor aconteça. Tradução de Luciene M. Garbuglio Castello Branco e Maristela M. Kondo Claus. In: Horizontes de Linguística Aplicada. Brasília: Editora Universidade de Brasília. Ano 2. p. 83-91, 2003.

SANTOS, Eduardo; MAGNO E SILVA, Walkyria. O efeito do aconselhamento linguageiro na trajetória de aprendizagem de uma estudante de inglês. In: MAGNO E SILVA; Walkyria; BORGES, Elaine Ferreira do Vale. Complexidade em ambientes de ensino e de aprendizagem de línguas adicionais. Curitiba: CRV, 2016. p. 139-158. https://doi.org/10.24824/978854441014.1

SILVA, Valdir. A Dinâmica Caleidoscópica do Processo de Aprendizagem Colaborativa no Contexto Virtual: um Estudo na Perspectiva da Complexidade/Caos. 2008. 237 f. (Doutorado em Linguística Aplicada). Faculdade de Letras. Programa de Pós-Graduação em Estudos Linguísticos, Universidade Federal de Minas Gerais, Belo Horizonte, 2008.

VAN LIER, Leo. From Input to Affordance: social-interactive learning from an ecological perspective. In.: LANTOLF, James P. (ed.) Sociocultural Theory and Second Language Learning. Oxford: Oxford University Press, 2000. p. 245-259. 
VIANINI, Caroline. Agência humana como um sistema adaptativo complexo: compreendendo o ensino de língua inglesa na escola pública e particular. ReVEL, v. 14, n. 27, 2016.

Recebido em: 01/06/2018

Aceito em: $18 / 10 / 2018$ 